\title{
The influence of physicians' specialty on prescribing patterns at a general medicine out-patients clinic
}

\section{Yaw A. Ofori-Adjei and Martina Fiakpornoo}

Ghana Med J 2019; 53(3): 204-209 doi: http://dx.doi.org/10.4314/gmj.v53i3.4

\author{
Department of Medicine and Therapeutics, Korle-Bu Teaching Hospital, Accra, Ghana
}

\author{
Corresponding author: Dr Yaw Ofori-Adjei \\ Conflict of interest: None declared
}

E-mail: yofori@gmail.com

\begin{abstract}
SUMMARY
Background: Several factors have been identified that influence physicians' prescribing habits. The influence of physician's specialty has not been studied. This study is to determine if there are differences in the prescribing patterns amongst these various specialities that run a general medicine clinic at a tertiary hospital in Ghana.

Methods: Data collected from the out-patients clinic attendance records were analysed using WHO Rational Use of Medicines indicators. Analysis of Variance Test was carried out to establish if there was any variance in the prescribing indicators amongst 4 units of Physicians.

Results: 678 patient encounters were utilised for this study. The average number of drugs prescribed per encounter was 4.4 , drugs prescribed by generic name was $86.9 \%$, patient encounters in which antibiotics prescribed were $6.5 \%$ $(\mathrm{n}=44)$ and injections were prescribed in $3.2 \%(\mathrm{n}=22)$ of patient encounters. $64.0 \%$ of all drugs prescribed were from the Ghanaian EML. The unit of the physician did not have a significant effect on the average number of medicines prescribed per patient encounter $(\mathrm{F}(3,674)=2.19, \mathrm{p}=0.088)$, and the percentage of medicines that were prescribed from the Essential Medicines List $(\mathrm{F}(3,674)=1.52, \mathrm{p}=0.207)$. The unit the physician belonged to however did have a significant effect at $\mathrm{p}<0.05$ on the prescription of generic medications $(\mathrm{F}(3,674)=4.79, \mathrm{p}=0.003)$.

Conclusion: The physician units did not differ in their prescribing patterns at the general medicine clinic except for prescription of drugs by their generic names.
\end{abstract}

Keywords: Rational Use of Medicines, Ghana, Prescribing Patterns, Physicians' Specialty

Funding: None declared

\section{INTRODUCTION}

The prescribing patterns of prescribers have severally been studied as a direct influencing factor on the rational use of medicines worldwide. With the World Health Organisation (WHO) estimating that more than half of all medicines are being prescribed, dispensed, or sold inappropriately ${ }^{1}$, there is a need to continuously study the factors that influence the prescribing habits of prescribers with the aim of decreasing the economic waste and morbidit $^{2}$ associated with irrational use of medicines.

In 1993, WHO and the International Network for the Rational Use of Drugs (INRUD) developed and published a standard methodology for selected drug use indicators in health facilities. ${ }^{3}$ Since then these indicators have been used in several international studies ${ }^{4-6}$. The WHO indicators have been used to identify problems in general prescribing and the quality of care at health care facilities. Results from the use of these indicators have helped identify the causes of irrational use and other problems in the use of medicines.
The data collected is then used to design appropriate interventions and subsequently used to assess the impact of those interventions. ${ }^{57-9}$ The core indicators are: (a) Average number of medicines prescribed per patient encounter, (b) Percentage of medicines prescribed by generic name, (c) Percentage of encounters with an antibiotic prescribed, (d) Percentage of encounters with an injection prescribed and (e) Percentage of medicines prescribed from an Essential Medicines List (EML) or formulary.

Although the WHO has not set specific targets for any of the prescribing indicators some desired reference ranges have been prescribed. In Ghana for instance, the Ghana National Drugs Programme has set out targets for health facilities to achieve. ${ }^{10}$ Prescribing habits of physicians has been shown to be influenced by several factors such as peer influence, financial considerations, activities of pharmaceutical representatives and advertising in journals and medical literature. 
One key area that has not been researched significantly is the effect of a physician's area of specialty on his prescribing habit when practicing general medicine. The WHO prescribing indicators have been used to measure the performance of health facilities against a set national target or used to compare performance of similarly structured health institutions within a region ${ }^{11}$ or internationally. These indicators give a summary of the prescribing habits of an institution. It has however not been used to assess if there are any differences in the prescribing habits of different specialities of physicians providing general medicine service in a common out-patients setting in a single institution.

For a large tertiary institution like the Korle-Bu Teaching hospital that has various specialty units running general medicine ambulatory clinic on specific days, the WHO prescribing indicators may be applied to the various groups of physicians to ascertain whether they have similar prescribing habits or not.

\section{METHODS}

\section{Study Design}

A records review was conducted on data that had been collected from the out-patients clinic attendance records of the Korle-Bu Teaching Hospital's department of medicine's general medicine outpatients' clinic, over a period of two months; February to March of 2013. This data had been collected in line with recommendation from the WHO Manual on how to investigate drug use in health facilities ${ }^{3}$. Ethical clearance with reference number MEt/M.11-P.3.2/2012-2013 was obtained from the Ethical and Protocol Committee of the School of Medicine and Dentistry of the College of Health Sciences of the University of Ghana.

\section{Study Site}

The Korle-Bu Teaching Hospital is a tertiary hospital and one of the postgraduate training facilities in Ghana. It is a 2000 bed capacity hospital and the largest referral centre in Ghana. It provides tertiary care in all the major medical disciplines. The Medical Department has four Physician Specialist (PS) teams, grouped into specialties; PS1 (Gastroenterology and Cardiology), PS2 (Endocrinology and Neurology), PS3 (Nephrology, Rheumatology and Respiratory medicine) and PS4 (Clinical Pharmacology, Dermatology, and Infectious Diseases). Each PS Team has an inpatient ward and also provides a general medicine out-patients clinic service on a specific day of the week.

\section{Study Population}

There are two categories of patients that attend the general medicine out-patients' clinic, patients discharged from the in-patient wards for follow up on out-patient basis or direct referrals to the clinic from other clinics within or outside the hospital. The clinic tends to see more chronic non-communicable disease such as hypertension, diabetes mellitus and other cardiovascular diseases rather than infectious diseases.

\section{Data collection and analysis}

Data on patient's demographics, diagnosis and prescribed drugs for every patient encounter was collected over a period of two months. Data collection was done by trained research assistants who were all pharmacists. They extracted information from the patients' folders and prescriptions into a data abstraction form. Data from the forms were entered into SPSS version 17 for statistical analysis.

The data was further stratified into 4 groups based on the units of the physicians. A null hypothesis that there was no difference in the prescribing indicators among the groups was made. Analysis of Variance Test was carried out to establish if there were any differences among the physician groups with respect to the prescribing indicators. A post hoc analysis using Tukey HSD was done to identify how the group varied for indicators for which the null hypothesis was rejected.

\section{RESULTS}

There were 678 patient encounters. The patient characteristics are shown in Table 1. The mean age of the study population was 58.6 years $(\mathrm{SD}=15)$, with the youngest patient having an age of 13 years and the oldest person being aged 97 .

Table 1 Characteristics of Patients attending the Medical OPD Clinic for the Study Period $(\mathrm{n}=678$

\begin{tabular}{l|l|} 
Patient Characteristics & \\
\hline $\begin{array}{l}\text { Gender - no (\%) } \\
\text { Male }\end{array}$ & $263(38.8 \%)$ \\
\hline $\begin{array}{l}\text { Female } \\
\text { Age - years }\end{array}$ & $415(61.2 \%)$ \\
\hline $\begin{array}{l}\text { Median (interquartile range) } \\
\text { Range }\end{array}$ & $59(21)$ \\
\hline $\begin{array}{l}\text { Number of Diagnosis made - no (\%) } \\
\text { PS 1 }\end{array}$ & $13-97$ \\
PS 2 & $315(46.7 \%)$ \\
PS 3 & $283(41.7 \%)$ \\
PS 4 & $73(10.8 \%)$ \\
\hline
\end{tabular}

Of the 678 patient encounters, a total of 1130 different diagnoses were made. Diseases of the circulatory system ranked number one, 59.9\% $(\mathrm{n}=677)$ followed by Endocrine, nutritional and metabolic diseases with $20.8 \%$ $(\mathrm{n}=235)$. Infections and parasitic diseases formed only $0.8 \%$ of all the diagnoses made. Figure 1 shows the summary distribution of the diagnoses made. 


\section{Original Article}

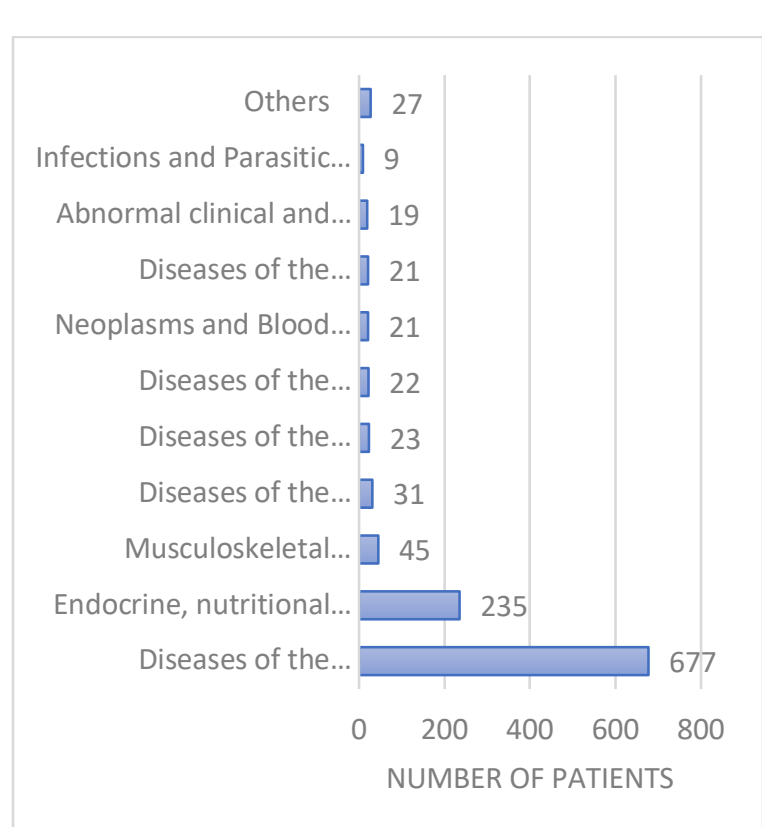

Figure 1 Distribution of Diagnoses of attendants at the Medical Outpatients Clinic

One Hundred and Sixty-One (161) different medications were prescribed. The mean number of medicines prescribed per encounter was $4.4(\mathrm{SD}=1.8)$. The minimum number of medicines prescribed per encounter was one and the highest number of medicines prescribed was ten. There were no patient encounters in which no medication was prescribed. Table 2 shows the performance of the various units by the WHO/INRUD Prescribing Indicators.

Table 2 WHO/INRUD Performance Indicators by different physician units

\begin{tabular}{|c|c|c|c|c|c|}
\hline \multirow[b]{2}{*}{$\begin{array}{l}\text { WHO/INRUD Prescribing } \\
\text { Indicator }\end{array}$} & \multicolumn{4}{|c|}{ Physician Specialist Team } & \multirow{2}{*}{$\begin{array}{l}\text { GNDP } \\
\text { Target }\end{array}$} \\
\hline & PS1 & PS2 & PS3 & PS4 & \\
\hline $\begin{array}{l}\text { Average number of medicines } \\
\text { prescribed per patient en- } \\
\text { counter }\end{array}$ & 4.3 & 4.4 & 4.6 & 4.1 & $<3.0$ \\
\hline $\begin{array}{l}\text { Percentage of medicines pre- } \\
\text { scribed by generic name (\%) }\end{array}$ & 67.1 & 57.6 & 62.8 & 67.5 & $100 \%$ \\
\hline $\begin{array}{l}\text { Percentage of encounters with } \\
\text { an antibiotic prescribed (\%) }\end{array}$ & 2.9 & 0.8 & 3.1 & 1.6 & $<30 \%$ \\
\hline $\begin{array}{l}\text { Percentage of encounters with } \\
\text { an injection prescribed (\%) }\end{array}$ & 0.4 & 1.4 & 0.6 & 0.7 & $<20 \%$ \\
\hline $\begin{array}{l}\text { Percentage of medicines pre- } \\
\text { scribed from the EML (\%) }\end{array}$ & 88.5 & 84.0 & 86.9 & 87.0 & $100 \%$ \\
\hline
\end{tabular}

A Levene's test for homogeneity of the variances for each performance indicator was carried out as a requirement for running their analysis of variance. The Levene's Test showed homogeneity of variance for the following indicators; Average number of medicines prescribed per patient encounter $(\mathrm{p}=0.69)$,
Percentage of medicines prescribed by generic name $(\mathrm{p}$ $=0.40$ ), and Percentage of medicines prescribed from the EML $(p=0.06)$. The Levene's Test for homogeneity failed for Percentage of encounters in which injections $(p=0.01)$ and antibiotics $(p=0.00)$ were prescribed.

Analysis of variance was carried out only on the indicators which passed the test for homogeneity. The unit the physician belonged to did not have a significant effect on the average number of medicines prescribed per patient encounter $(F(3,674)=2.19, p=0.088)$, and the percentage of medicines that were prescribed from the Essential Medicines List $(\mathrm{F}(3,674)=1.52, \mathrm{p}=0.207)$. The unit the physician belonged, however, did have a significant effect at $\mathrm{p}<0.05$ on the prescription of generic medications $(\mathrm{F}(3,674)=4.79, \mathrm{p}=0.003)$.

Post hoc comparisons using the Tukey HSD test showed that the percentage of generic prescription of medicines by PS2 $(\mathrm{M}=57.64, \mathrm{SD}=0.28)$ was $9.8 \%$ less than PS4 $(\mathrm{M}=67.50, \mathrm{SD}=0.26)$ and $9.5 \%$ when compared to PS1 $(\mathrm{M}=67.10, \mathrm{SD}=0.27)$ but there was no statistical difference when compared to PS3 ( $\mathrm{M}=62.81, \mathrm{SD}=0.26)$.

The results therefore do suggest that specialties of the various teams do not have an effect on the prescribing behaviours for indicators such as average number of drug prescribed per patient encounters and on the percentage of drugs prescribed from the essential medicines list. However, prescription of drugs by their generic name may be affected by the specialty of the physician team.

\section{DISCUSSION}

\section{Prescribing Indicators}

The WHO/INRUD indicators have been used in several studies to assess the performance of prescribers in many health facilities worldwide. It has however not been used to assess how the speciality of a prescribers may affect their prescribing habits in a general medicine out-patients clinic where patients with similar disease conditions are seen.

The setup of the Korle-Bu Teaching Hospitals out-patients clinic afforded us the opportunity to do so. The data analysed was collected over a two month period only and thus could be affected by seasonal variation in the diseases that present at the clinic and therefore the type of medicines prescribed. This limitation notwithstanding, the nature of the general medicine outpatients clinic which sees predominantly chronic non-communicable diseases, did provide a homogenous dataset from which prescribing patterns could be studied. 


\section{Original Article}

Methods for the development of reference values for the indicators peculiar to the local setting have been developed. This has been achieved by the combination of local clinical case mix data and consensus treatment guidelines for major disease entities ${ }^{12}$. Every year, the Ghana National Drugs Program (GNDP) sets out national targets for the WHO/INRUD indicators. These set targets are for non-specialist out-patient use but are applicable to specialist clinics where patients with multiple morbidities are seen.

Comparing the overall performance of the department against the national target set by the Ghana National Drugs program for the year of the study; this study showed that the average number of drugs prescribed per patient encounter was higher (4.39) than the national target of 3.0. The target of $100 \%$ for drugs prescribed from the EML and drugs prescribed by the generic name were not met at $64.0 \%$ and $86.9 \%$ respectively. However, there was better performance for indicators; percentage per encounter of antibiotics $(6.5 \%)$ prescribed and injections prescribed (3.2\%) compared to the national targets of below $30 \%$ and below $20 \%$ respectively.

The average number of drugs prescribed per patient encounter was higher than the national target of 3.0 which suggests the presence of polypharmacy. However looking at the disease profile of the attendants to the OPD, more than $70 \%$ were diagnosed with non-communicable cardiovascular disease of Hypertension and Hypertension related diseases, diabetes, strokes, and hyperlipidaemia. Also, more than $50 \%$ of them had 2 or more comorbid conditions. These factors may explain why the average number of drugs prescribed per encounter is higher than the national target.

Majority of the attendants at the clinic, as showed by the disease profile (Figure 1), are chronic non-communicable disease. Infections and Parasitic Diseases constituted $0.8 \%$ of all diagnoses made. The majority of conditions do not fall within the category of disease which will require injections and antibiotics. The clinic set-up is also such that any patient requiring emergency care is sent to the emergency room where they are more likely to have injections i.e. IV or IM medications administered. These factors may explain the very minimal use of injections and antibiotics and therefore the seemly better performance on indicators; percentage per encounter of antibiotics prescribed and percentage per encounter of injections prescribed.

The percentage of drugs prescribed from the Ghana EML was low; $86.9 \%$. The inability to achieve the target of $100 \%$ may be due to the unavailability of the EML in the all the consulting rooms of the OPD.
Being a tertiary referral centre as well, it is likely that the drugs required to treat the many complex cardiovascular and metabolic diseases such as second line drug choices are not present in the EML hence requiring prescriptions outside it.

Prescription by generic name is desired at $100 \%$. Use of branded drugs is associated with comparatively higher treatment costs, difficulty of remembering the medication, accessibility to the medicines by patients. The measured performance of $64.0 \%$ in this study is below the target and comparable to that gotten from similar studies done in Osun State in Nigeria of $69.8 \%$ and $70.2 \%$ in Jos University Teaching Hospital Nigeria ${ }^{13}$.

Activities of medical representatives of pharmaceutical companies may be responsible for the high rate of prescription by brand names. Medical representatives of these pharmaceutical companies pay visits to doctors during the OPD clinics, on the inpatient wards and in the physicians' offices. Although no study has been carried out to measure the influence of medical representatives on the prescribing behaviour of doctors in Ghana, a study done in University College Hospital, Ibadan, Nigeria showed that $93.2 \%$ of doctors reported that they sourced drug information from Pharmaceutical Sales Representative (PSR) and more than $50 \%$ of respondents considered information from these PSR as accurate and reliable ${ }^{14}$.

A systematic review that examined the relationship between exposure to information from pharmaceutical companies and the quality, quantity, and cost of physicians' prescribing showed that studies of exposure to information provided directly by pharmaceutical companies have found associations with higher prescribing frequency, higher costs, or lower prescribing quality ${ }^{15}$. This same systematic review did not find any evidence of improvement in prescribing from the use of information provided by pharmaceutical companies.

\section{Effect of Physicians' Specialty on Prescribing Indica- tors}

Variance in the prescribing indicators of percentage of antibiotics and percentage of injections prescribed per patient of encounter were not assessed because they did not pass the test for homogeneity. This is due to the fact that numbers realised for both indicators where so small for the whole department and varied widely between the four groups. For the remaining indicators that passed the Levene's test for homogeneity; there was no significant difference in the average number of drugs that were prescribed per patient encounter nor was there a significant difference in the percentage of drugs that was prescribed from the EML among the four physician groups. 
There was however significant variance in the prescription of branded drugs amongst the physician groups.

Significantly PS2's (Neurology and Endocrine) prescriptions of generic drugs was $9.8 \%$ less than that of PS4 (Clinical Pharmacology, Dermatology and Infectious Diseases), 9.5\% less than PS1 (Cardiovascular and Gastroenterology) but with no significant difference when compared to PS3 (Respiratory and Renal). PS4 therefore performed best amongst the 4 teams when it came to prescribing of drugs by the generic names while the PS2 team appeared the most likely influenced by their specialties to prescribe more branded name drugs than generic drugs.

Generic prescribing results in lower pharmaceutical cost and increased access to medicines. This is particularly important in Ghana where healthcare financing is a problem. Data on the impact of generic prescribing is lacking in Ghana and indeed in the sub-Saharan region. The United States Congressional Budget Office estimates that between $\$ 8$ Billion and \$10 Billion per year is saved for the consumer from generic drugs prescriptions at retail pharmacies alone. Billions more are saved when hospitals and healthcare providers use generic options. ${ }^{16}$

The benefits of cost-saving and the general improved access to medicines notwithstanding, reasons why prescribers and indeed the patients themselves may have little faith in the generic drugs is that they are sometimes confused with being fake drugs and of inferior quality. ${ }^{17}$ These perceptions have been further fuelled by recent reports of fake drugs on the Ghanaian market ${ }^{18}$. It would thus be understandable if particular specialties preferred the used of particular branded drugs at their specialty clinics from past experience on their efficacy. However in the general medicine out-patients' clinic, it is expected that physicians, irrespective of training and specialties, would have similar patterns of prescribing of generic medications.

The results of our study did show that the PS4 team did perform the best when it came to the generic prescriptions of medications as indeed it did for all the other prescribing indicators for which the tests of homogeneity was passed albeit not being statistically significant. The PS4 team has the specialty of Clinical Pharmacology and Therapeutics. It might therefore be argued that their training did have a positive influence on their prescribing habits. This therefore serves as opportunity to intensify the efforts to promote generic prescribing amongst the various physician groups.

\section{CONCLUSION}

The prescribing patterns of physicians at the medical outpatients' clinic were sub-optimal when compared to the national set targets and thus requires measures to optimize drug prescribing habits of physicians. The various physician groups did not very much in their prescribing patterns when it came to average number of drugs prescribed per encounter and prescription from the EML. There was however a significant difference in prescribing by generic names. The group that had Clinical Pharmacologists performed best. This study showed that the specialty of prescribers did affect their prescribing of medicines by generic names. Interventions to improve the use of generic names when prescribing needs to be incorporated into prescribing practice guidelines.

\section{REFERENCES}

1. Hogerzeil HV. Promoting rational prescribing: an international perspective. $\mathrm{Br} \mathrm{J}$ Clin Pharmacol 1995;39(1):1-6.

2. Andel C, Davidow SL, Hollander M, et al. The economics of health care quality and medical errors. $J$ Health Care Finance 2012;39(1):39-50.

3. How to Investigate Drug Use in Health Facilities: Selected Drug Use Indicators World Health Organization, 1993.

4. Maiga D, Diawara A, Maiga MD. [Evaluation of rational prescribing and dispensing of medicines in Mali]. Rev Epidemiol Sante Publique 2006;54(6):497-505.

5. Mallet HP, Njikam A, Scouflaire SM. [Evaluation of prescription practices and of the rational use of medicines in Niger]. Sante 2001;11(3):185-93.

6. Otoom S, Batieha A, Hadidi H, et al. Evaluation of drug use in Jordan using WHO prescribing indicators. East Mediterr Health J 2002;8(4-5):537-43.

7. Hogerzeil HV, Bimo, Ross-Degnan D, et al. Field tests for rational drug use in twelve developing countries. Lancet 1993;342(8884):1408-10.

8. Obua C, Ogwal-Okeng JW, Waako P, et al. Impact of an educational intervention to improve prescribing by private physicians in Uganda. East Afr Med J 2004;Suppl:S17-24.

9. Ross-Degnan D, Laing R, Quick J, et al. A strategy for promoting improved pharmaceutical use: the International Network for Rational Use of Drugs. Soc Sci Med 1992;35(11):1329-41.

10. Ghana National Drugs Policy. Second Edition ed: Ghana National Drugs Programme, 2004.

11. Mahmood A, Elnour AA, Ali AAA, et al. Evaluation of rational use of medicines (RUM) in four government hospitals in UAE. Saudi Pharmaceutical Journal 2016;24(2):189-96. 
12. AO Isah RL, J. Quick, A.F.B. Mabadeje, B. Santoso, H. Hogerzeil, D. Ross-Degnan. The Development of Reference Values for the WHO Health Facility Core Prescribing Indicators. West African Jnl of Pharmacology and Drug Research 2002;18:611.

13. Ndukwe H, Ogaji I, Sariem C. Drug use pattern with standard indicators in Jos University Teaching Hospital Nigeria. West African Journal of Pharmacy 2013;24(1):88-93.

14. Oshikoya KA, Oreagba I, Adeyemi O. Sources of drug information and their influence on the prescribing behaviour of doctors in a teaching hospital in Ibadan, Nigeria. Pan Afr Med J 2011;9:13.

15. Spurling GK, Mansfield PR, Montgomery BD, et al. Information from pharmaceutical companies and the quality, quantity, and cost of physicians' prescribing: a systematic review. PLoS Med 2010;7(10):e1000352.
16. United States. Congress. Senate. Committee on Health Education Labor and Pensions. Generic drug user fee amendments: accelerating patient access to generic drugs: hearing of the Committee on Health, Education, Labor, and Pensions, United States Senate, One Hundred Fourteenth Congress, second session on examining generic drug user fee amendments, focusing on accelerating patient access to generic drugs, January 28, 2016. Washington, DC: U.S. Government Publishing Office, 2018.

17. Patel A, Gauld R, Norris P, et al. Quality of generic medicines in South Africa: perceptions versus reality - a qualitative study. BMC Health Serv Res 2012;12:297.

18. Kaku D. Caution: Substandard, fake drugs in Ghana: Mordern Ghana; 2018 [Available from: https:/www.modernghana.com/news/875471/caution-substandard-fake-drugs-in-ghana.html. 